\title{
Estimasi Ancaman Tsunami di Zona Subduksi Sulawesi Bagian Utara Sebagai Upaya Mitigasi Bencana Tsunami
}

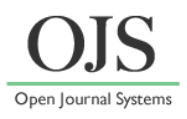

\author{
Wahyu Kurniawan*, Ernalem Bangun, Bondan Prakoso \\ Program Studi Manajemen Bencana, Fakultas Keamanan Nasional, Universitas Pertahanan. \\ *Email: ernalem.bangun@idu.ac.id \\ DOI: https://doi.org/10.33369/pendipa.5.2.204-209
}

\begin{abstract}
Sulawesi Island is very prone to earthquakes. This is due to the meeting of three tectonic plates, namely the Eurasian Plate, the Philippine Plate, and the Indo-Australian Plate. In northern Sulawesi, there is also a micro plate, namely the Sulawesi Sea Plate, as a result of the movement of the Sulawesi Sea Plate, a subduction zone or subduction zone is formed. The subduction zone in the Sulawesi Sea Plate is known as the North Sulawesi Megathrust. If an earthquake with a very large magnitude occurs in the Megathrust Zone of North Sulawesi which has the potential for a tsunami, it is necessary to estimate the tsunami threat using the Tsunami Observation and Simulation Terminal (TOAST) to find out the tsunami simulation modeling that produces important information such as the arrival time of the tsunami, locations with the potential for a tsunami and the maximum tsunami height will occur as disaster mitigation measures. The method used is a qualitative method with descriptive analytical type. To obtain research data, data provision techniques are used with literature study and field studies. The research results in the form of tsunami threat modeling indicate that locations close to the epicenter of the earthquake have a potential tsunami threat with a warning status, namely in Buol, Minahasa Islands, northern Bolaang Mongondow and northern Gorontalo. Meanwhile, locations that have standby status are Manado City, northern Minahasa, Toli-Toli and northern South Minahasa. From the results of tsunami modeling, it was found that the maximum height of the tsunami reached 5.74 meters in northern Gorontalo. The ability of all components of society and local government is needed to form community resilience that is potentially affected, especially in facing the threat of a tsunami disaster in the Megathrust Zone of North Sulawesi. Thus, disaster risk can be reduced or suppressed.
\end{abstract}

Keywords: North Sulawesi Megathrust Zone, Tsunami, TOAST.

\begin{abstract}
ABSTRAK
Pulau Sulawesi sangat rawan akan terjadinya gempabumi. Hal ini disebabkan oleh bertemunya tiga lempeng tektonik, yakni Lempeng Eurasia, Lempeng Filipina, dan Lempeng Indo-Australia. Di Sulawesi bagian utara juga terdapat lempeng mikro yakni Lempeng Laut Sulawesi, akibat dari pergerakan Lempeng Laut Sulawesi tersebut maka terbentuklah zona subduksi atau zona penunjaman. Zona subduksi pada Lempeng Laut Sulawesi tersebut yang dikenal dengan nama Megathrust Sulawesi Utara. Jika terjadi gempabumi dengan magnitudo yang sangat besar terjadi di Zona Megathrust Sulawesi Utara yang berpotensi terjadinya tsunami, maka perlu dibuat estimasi ancaman tsunami dengan menggunakan Tsunami Observation and Simulation Terminal (TOAST) untuk mengetahui permodelan simulasi tsunami yang menghasilkan informasi-informasi penting seperti waktu tiba tsunami, lokasi-lokasi yang berpotensi tsunami dan ketinggian maksimum tsunami akan terjadi sebagai upaya mitigasi bencana. Metode yang digunakan adalah metode kualitatif dengan jenis deskriptif analitis. Untuk memperoleh data penelitian, digunakan teknik penyediaan data dengan studi pustaka dan studi di lapangan. Hasil penelitian berupa pemodelan ancaman tsunami menunjukkan bahwa lokasi-lokasi yang berdekatan dengan episentrum gempabumi memiliki potensi ancaman tsunami yang berstatus awas yakni di Buol, Kepulauan Minahasa, Bolaang Mongondow bagian utara dan Gorontalo bagian utara. Sedangkan lokasi yang berstatus siaga yakni Kota Manado, Minahasa bagian utara, Toli-Toli dan Minahasa Selatan bagian utara. Dari hasil pemodelan tsunami diperoleh ketinggian maksimum tsunami mencapai 5.74 meter di Gorontalo bagian utara. Kemampuan seluruh komponen masyarakat dan pemerintah
\end{abstract}


daerah sangat diperlukan untuk membentuk resiliensi masyarakat yang berpotensi terdampak, khususnya dalam menghadapi ancaman bencana tsunami di Zona Megathrust Sulawesi Utara. Dengan demikian, risiko bencana tersebut dapat dikurangi atau ditekan.

Kata kunci: Zona Megathrust Sulawesi Utara, Tsunami, TOAST.

\section{PENDAHULUAN}

Pulau Sulawesi merupakan salah satu pulau yang sangat rawan terjadinya gempabumi. Hal ini disebabkan oleh bertemunya tiga lempeng tektonik, yaitu Lempeng Eurasia, Lempeng Filipina, dan Lempeng Indo-Australia. Selain 3 lempeng tersebut, juga terdapat lempeng mikro di Sulawesi bagian utara yang terbentuk dari hasil subduksi kerak samudra yang terdapat di Laut Sulawesi yang disebut sebagai Lempeng Laut Sulawesi. Aktifitas Lempeng Laut Sulawesi membentuk zona subduksi atau zona penunjaman yang dapat diilustrasikan pada Gambar 1.

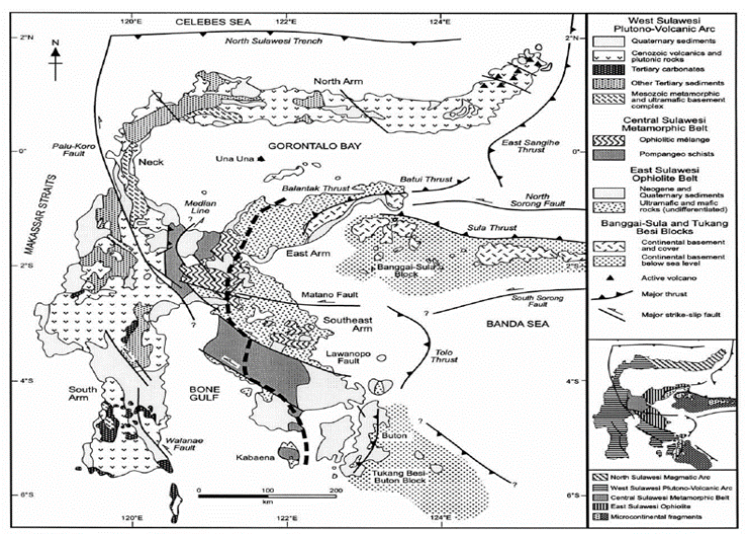

Gambar 1. Geologi regional Pulau Sulawesi

(Sumber: Hall, R., and Wilson, M.E.J., 2000).

Zona subduksi pada Lempeng Laut Sulawesi dikenal dengan nama Megathrust Sulawesi Utara. Kecepatan pergeseran geodetik Megathrust Sulawesi Utara mencapai 42-50 $\mathrm{mm} / \mathrm{thnn}$ (Socquet et al., 2006). Zona segmentasi subduksi Megathrust Sulawesi Utara ditunjukkan pada Gambar 2.

Berdasarkan Peta Segmentasi dan Magnitudo Maksimum Subduksi Indonesia tersebut, maka Megathrust Sulawesi Utara dapat mengakibatkan gempabumi dengan magnitudo yang besar, yakni M 8.5. Apabila potensi magnitudo mencapai angka tersebut, tentu dapat menjadi sumber pembangkit tsunami di Sulawesi bagian utara (Wahyu, 2018).

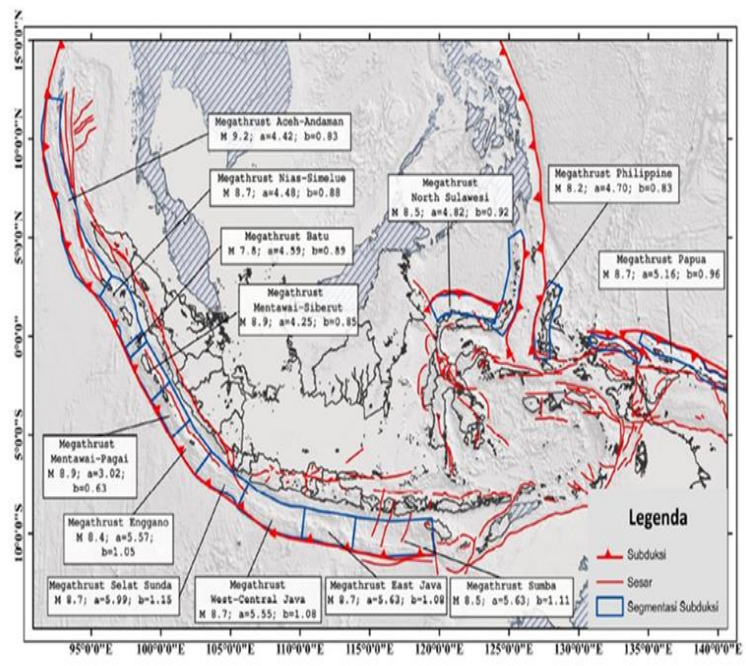

Gambar 2. Peta Segmentasi dan Magnitudo Maximum Subduksi Indonesia (Sumber: Pusat Studi Gempa Nasional, 2017).

Dalam 25 tahun belakangan, terjadi dua aktivitas gempabumi dengan magnitudo yang besar. Pertama, pada 1 Januari 1996 terjadi gempabumi dengan magnitudo 7,9 di sebelah utara Toli-Toli yang mengakibatkan tsunami. Kedua, gempabumi pada 16 November 2008 bermagnitudo 7,3 di utara Gorontalo yang berpotensi tsunami dan menimbulkan kerugian jiwa serta kerugian materil (Setiyono, 2018).

Dengan adanya potensi gempabumi yang besar disertai dengan tsunami di Sulawesi bagian utara, maka perlu dibuat estimasi ancaman tsunami dengan menggunakan aplikasi TOAST (Tsunami Observation and Simulation Terminal). TOAST adalah perangkat lunak untuk simulasi pemodelan dan verifikasi tsunami yang memberikan penilaian bahaya secara cepat (www.gempa.de/products/toast). Simulasi pemodelan potensi tsunami menggunakan TOAST menghasilkan informasi-informasi penting, misalnya waktu tiba gelombang tsunami, ketinggian air tsunami (run up), dan status (awas, siaga dan waspada) tsunami. Estimasi ancaman tsunami dengan menggunakan TOAST sangat membantu untuk mitigasi bencana tsunami agar 
risiko atau kerugian akibat bencana dapat dikurangi.

Merujuk pada UU No 24 Tahun 2007, mitigasi bencana dimaknai sebagai upaya atau usaha yang dilaksanakan untuk menekan risiko bencana yang diwujudkan dengan pembangunan fisik serta nonfisik melalui kegiatan penyadaran dan peningkatan kapasitas dalam menghadapi ancaman bencana. Guna mendukung keberhasilan dalam upaya mitigasi bencana tsunami, maka diharapkan Pemerintah Daerah dan masyarakat harus mempunyai kesiapsiagaan menghadapi ancaman tsunami dengan berbagai cara. Pertama, turut serta dalam mengamankan dan menjaga peranti detektor bencana yang ada di wilayahnya. Kedua, membangun peta risiko tsunami beserta skenario penyelamatan. Ketiga, membangun tempat evakuasi tsunami beserta peta aksesibilitasnya. Keempat, menginstal ramburambu berupa plang petunjuk atau penunjuk arah evakuasi tsunami. Kelima, mempersiapkan pusat krisis/pusat komando. Keenam, melakukan dril evakuasi tsunami secara berkelanjutan. Keenam, menyebar sirine tsunami. Ketujuh, membangun selter penyelamatan. Kedelapan, mengakomodasi pertimbangan kebencanaan dalam penyusunan tata-ruang. Terakhir, mengintegrasikan pendidikan kebencanaan ke sekolah melalui muatan lokal kurikulum untuk semua jenjang pendidikan (BMKG, 2010).

Ketangguhan masyarakat akan terwujud jika memiliki kemampuan untuk mendeteksi berbagai macam ancaman atau bahaya yang potensial (Maarif, 2012). Oleh karena itu, dalam penelitian ini dilakukan prediksi, identifikasi, serta asesmen terhadap risiko bencana tsunami.

\section{METODE PENELITIAN}

Dalam penelitian ini, digunakan metode kualitatif dengan jenis deskriptif analitis. Untuk memperoleh data penelitian, digunakan teknik penyediaan data dengan studi pustaka dan studi di lapangan. Studi pustaka dilaksanakan dengan mengasosiasi seluruh referensi yang terkait dengan penelitian, misalnya peta-peta yang bersumber dari instansi pemerintah, jurnal ilmiah, katalog gempabumi merusak, dan data-data yang berasal dari situs web. Sementara itu, penelitian di lapangan dilakukan dengan cara mengoperasikan aplikasi TOAST di ruangan operasional
InaTEWS (Indonesia Tsunami Warning System) milik BMKG Pusat Jakarta.

Waktu penelitian dilakukan pada Tanggal 25 Desember 2020 dan lokasi penelitian di ruang operasional Inatews (Indonesia Tsunami Warning System) BMKG Pusat Jakarta.

\section{HASIL DAN PEMBAHASAN}

Gempabumi yang mengakibatkan tsunami memiliki syarat-syarat tertentu, yakni episentrum berada di laut, memiliki magnitudo besar $M>7.0$ SR, secara khusus kedalaman pusat gempa cenderung dangkal (kurang dari $70 \mathrm{~km}$ ), serta mekanisme penyesaran berupa sesar naik atau sesar turun (BMKG, 2010). Potensi gempabumi di jalur subduksi Megathrust Sulawesi Utara menurut Pusat Studi Gempa Nasional (PUSGEN) memiliki magnitudo M 8.5. Oleh karena itu, peneliti melakukan pemodelan ancaman tsunami menggunakan aplikasi TOAST yang dilaksanakan pada 25 Desember 2020, dengan parameterparameter gempabumi, antara lain: Origin Time (waktu kejadian gempabumi) 07:30:05 UTC/14:30:05 WIB, Magnitudo M 8.5, kedalaman $10 \mathrm{~km}$, serta lokasi $1.40^{\circ} \mathrm{LU}$ dan $122.00^{\circ} \mathrm{BT}$. Hasil dari pemodelan yang dimaksud dapat diamati pada Gambar 3 dan Gambar 4.

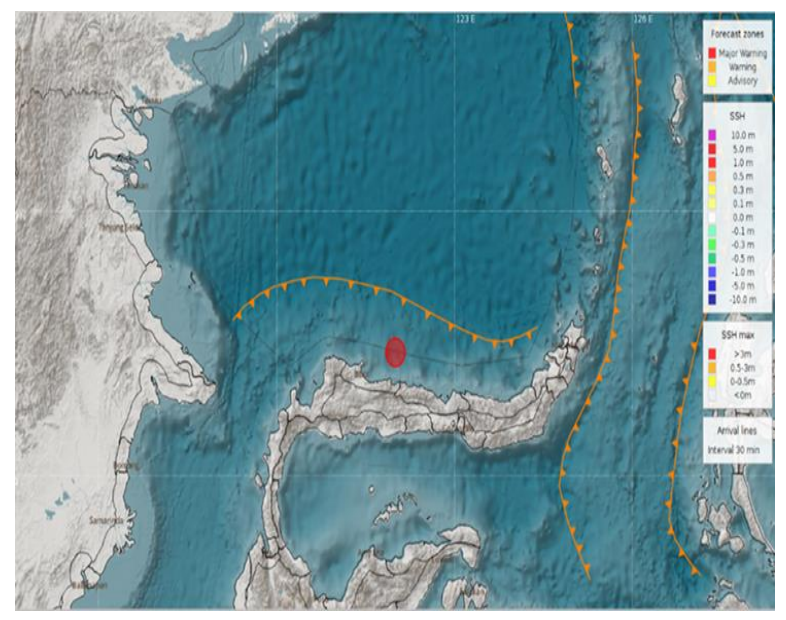

Gambar 3. Letak episenter gempabumi pada zona subduksi Megathrust Sulawesi Utara

(Sumber: peneliti, 2020).

Pada Gambar 3, terlihat pusat gempabumi yang ditandai oleh simbol bulat berwarna merah yang terletak di antara zona subduksi Megathrust Sulawesi Utara dengan Pulau Sulawesi. Pusat gempabumi ditentukan di lokasi tersebut agar 
pemodelan ancaman tsunami dapat terlihat dengan jelas dan merata penyebarannya.

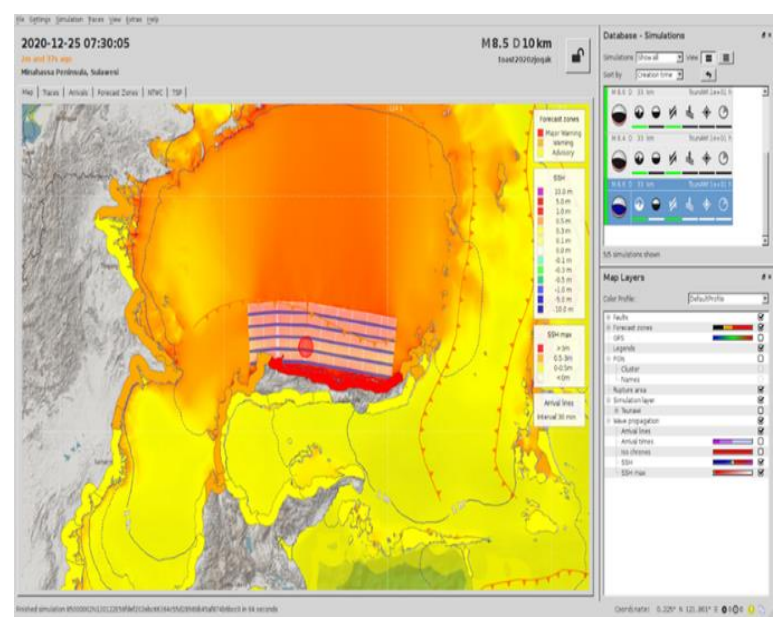

Gambar 4. Hasil permodelan ancaman tsunami pada jalur subduksi Megathrust Sulawesi Utara (Sumber: peneliti, 2020).

Gambar 4 merupakan hasil permodelan ancaman tsunami pada zona subduksi Megathrust Sulawesi Utara. Dari pemodelan tersebut, dipilih pemodelan TsunAWI dengan magnitudo M 8.6 karena penjalaran gelombang tsunami dapat dilihat dengan interval waktu lebih dari 24 jam dan lokasi penjalaran gelombang tsunami semakin luas ke segala arah. Hal ini telah ditunjukkan oleh Gambar 3 bahwa ancaman tsunami ditandai dengan warna merah yang berarti awas dengan ketinggian air tsunami lebih dari 3 meter, warna oranye berarti berstatus siaga dengan ketinggian air tsunami antara 0.5 meter sampai 3 meter, warna kuning berstatus waspada dengan ketinggian air tsunami kurang dari 0.5 meter, serta warna putih berarti berstatus tidak terdampak dengan ketinggian air tsunami 0 meter.

Dari pemodelan ancaman tsunami dengan menggunakan TOAST, didapatkan lokasi-lokasi yang berpotensi terjadinya tsunami dengan status awas, siaga, dan waspada yang dapat dilihat pada Tabel 1.

Pada Gambar 4, telah diperlihatkan juga lokasi-lokasi yang berdekatan dengan episentrum gempabumi yang memiliki status awas dan siaga dengan ketinggian maksimum tsunami yang dapat dilihat pada Tabel 2 .
Tabel 1. Tabel wilayah-wilayah yang berpotensi terjadi tsunami.

\begin{tabular}{|c|c|c|c|}
\hline Tanggal & $\begin{array}{c}\text { Waktu } \\
\text { Tiba } \\
\text { Tsunami }\end{array}$ & Status & Lokasi \\
\hline 25 & $14: 37: 05$ & Awas & Buol, Provinsi \\
\hline $\begin{array}{c}\text { Desember } \\
2020\end{array}$ & WIB & & $\begin{array}{l}\text { Sulawesi } \\
\text { Tengah }\end{array}$ \\
\hline $\begin{array}{c}25 \\
\text { Desember } \\
2020\end{array}$ & $\begin{array}{c}\text { 14:39:05 } \\
\text { WIB }\end{array}$ & Awas & $\begin{array}{l}\text { Kepulauan } \\
\text { Minahasa, } \\
\text { Provinsi } \\
\text { Sulawesi Utara }\end{array}$ \\
\hline $\begin{array}{c}25 \\
\text { Desember } \\
2020\end{array}$ & $\begin{array}{c}\text { 14:42:05 } \\
\text { WIB }\end{array}$ & Awas & $\begin{array}{l}\text { Bolaang } \\
\text { mongondow } \\
\text { bagian utara, } \\
\text { Provinsi } \\
\text { Sulawesi Utara }\end{array}$ \\
\hline $\begin{array}{c}25 \\
\text { Desember } \\
2020\end{array}$ & $\begin{array}{c}\text { 14:42:05 } \\
\text { WIB }\end{array}$ & Awas & $\begin{array}{l}\text { Gorontalo } \\
\text { bagian utara, } \\
\text { Provinsi } \\
\text { Gorontalo }\end{array}$ \\
\hline $\begin{array}{c}25 \\
\text { Desember } \\
2020\end{array}$ & $\begin{array}{c}\text { 14:37:05 } \\
\text { WIB }\end{array}$ & Siaga & $\begin{array}{l}\text { Kota Manado, } \\
\text { Provinsi } \\
\text { Sulawesi Utara }\end{array}$ \\
\hline $\begin{array}{c}25 \\
\text { Desember } \\
2020\end{array}$ & $\begin{array}{c}\text { 14:38:05 } \\
\text { WIB }\end{array}$ & Siaga & $\begin{array}{l}\text { Minahasa } \\
\text { bagian utara, } \\
\text { Provinsi } \\
\text { Sulawesi Utara }\end{array}$ \\
\hline $\begin{array}{c}25 \\
\text { Desember } \\
2020\end{array}$ & $\begin{array}{c}\text { 14:38:05 } \\
\text { WIB }\end{array}$ & Siaga & $\begin{array}{l}\text { Toli-Toli, } \\
\text { Provinsi } \\
\text { Sulawesi } \\
\text { Tengah }\end{array}$ \\
\hline $\begin{array}{l}25 \\
\text { Desember } \\
2020\end{array}$ & $\begin{array}{l}\text { 14:39:05 } \\
\text { WIB }\end{array}$ & Siaga & $\begin{array}{l}\text { Minahasa } \\
\text { Selatan bagian } \\
\text { utara, Provinsi } \\
\text { Sulawesi Utara }\end{array}$ \\
\hline
\end{tabular}




\begin{tabular}{|c|c|c|c|}
\hline 25 & $15: 05: 05$ & Waspada & Minahasa \\
\hline Desember & WIB & & bagian selatan, \\
\hline \multirow[t]{2}{*}{2020} & & & Provinsi \\
\hline & & & Sulawesi Utara \\
\hline 25 & 15:13:05 & Waspada & Bulungan, \\
\hline Desember & WIB & & Provinsi \\
\hline \multirow[t]{2}{*}{2020} & & & Kalimantan \\
\hline & & & Timur \\
\hline 25 & $15: 18: 05$ & Waspada & Kota Ternate, \\
\hline Desember & WIB & & Provinsi \\
\hline 2020 & & & Maluku Utara \\
\hline 25 & $15: 19: 05$ & Waspada & Mamuju bagian \\
\hline Desember & WIB & & utara, Provinsi \\
\hline 2020 & & & Sulawesi Barat \\
\hline
\end{tabular}

Sumber: Hasil Analisis Pemodelan Tsunami Menggunakan TOAST, 2020

Tabel 2. Tabel wilayah-wilayah yang berpotensi terjadi tsunami yang berdekatan dengan episentrum gempabumi.

\begin{tabular}{cccc}
\hline Lokasi & $\begin{array}{c}\text { Waktu Tiba } \\
\text { Tsunami }\end{array}$ & Status & $\begin{array}{c}\text { Ketinggian } \\
\text { Air } \\
\text { Tsunami } \\
(\text { Run Up })\end{array}$ \\
\hline Buol, & $14: 37: 05$ & Awas & 4.79 meter \\
Provinsi & WIB & & \\
Sulawesi & & & \\
Tengah & & & \\
\hline Kepulauan & $14: 39: 05$ & Awas & 3.11 meter \\
Minahasa, & WIB & & \\
Provinsi & & & \\
Sulawesi & & & \\
Utara & & & \\
\hline Bolaang & $14: 42: 05$ & Awas & 4.83 meter \\
Mongondow & WIB & & \\
bagian utara, & & & \\
\hline
\end{tabular}

\begin{tabular}{|c|c|c|c|}
\hline $\begin{array}{c}\text { Provinsi } \\
\text { Sulawesi } \\
\text { Utara }\end{array}$ & & & \\
\hline $\begin{array}{c}\text { Gorontalo } \\
\text { bagian utara, } \\
\text { Provinsi } \\
\text { Gorontalo }\end{array}$ & $\begin{array}{c}\text { 14:42:05 } \\
\text { WIB }\end{array}$ & Awas & 5.74 meter \\
\hline $\begin{array}{c}\text { Kota } \\
\text { Manado, } \\
\text { Provinsi } \\
\text { Sulawesi } \\
\text { Utara }\end{array}$ & $\begin{array}{c}\text { 14:37:05 } \\
\text { WIB }\end{array}$ & Siaga & 1.93 meter \\
\hline $\begin{array}{c}\text { Minahasa } \\
\text { bagian utara, } \\
\text { Provinsi } \\
\text { Sulawesi } \\
\text { Utara }\end{array}$ & $\begin{array}{c}\text { 14:38:05 } \\
\text { WIB }\end{array}$ & Siaga & 2.76 meter \\
\hline $\begin{array}{c}\text { Toli-Toli, } \\
\text { Provinsi } \\
\text { Sulawesi } \\
\text { Tengah }\end{array}$ & $\begin{array}{c}\text { 14:38:05 } \\
\text { WIB }\end{array}$ & Siaga & 2.21 meter \\
\hline $\begin{array}{c}\text { Minahasa } \\
\text { Selatan } \\
\text { bagian utara, } \\
\text { Provinsi } \\
\text { Sulawesi } \\
\text { Utara }\end{array}$ & $\begin{array}{c}\text { 14:39:05 } \\
\text { WIB }\end{array}$ & Siaga & 2.14 meter \\
\hline
\end{tabular}

Sumber: Hasil Analisis Pemodelan Tsunami Menggunakan TOAST, 2020.

\section{KESIMPULAN}

Zona subduksi Megathrust Sulawesi Utara merupakan daerah yang memiliki potensi gempabumi dengan magnitudo yang sangat besar sehingga dapat mengakibatkan tsunami. Jika terjadi gempabumi dengan magnitude M 8.5 pada jam 14:30:05 WIB dengan permodelan tsunami menggunakan TOAST di zona subduksi Megathrust Sulawesi Utara, maka akan mengakibatkan terjadinya potensi tsunami di 4 
lokasi dengan status awas, yakni Buol (4,79 meter), Kepulauan Minahasa (3,11 meter), Bolaang Mongondow bagian utara (4,83 meter), dan Gorontalo bagian utara $(5,74$ meter $)$. Sementara itu, didapat 4 lokasi dengan status siaga, yaitu Kota Manado (1,93 meter), Minahasa bagian utara (2,76 meter), Toli-Toli (2,21 meter), dan Minahasa Selatan bagian utara (2,14 meter). Berdasarkan hasil kajian, dapat dijabarkan beberapa saran yang ditujukan kepada Pemerintah Provinsi Sulawesi Tengah, Provinsi Gorontalo, dan Provinsi Sulawesi Utara pada tiga poin berikut:

1. Pemerintah Provinsi Sulawesi Tengah, Provinsi Gorontalo dan Provinsi Sulawesi Utara harus aktif menyosialisasikan potensi gempabumi dan tsunami pada zona subduksi Megathrust Sulawesi Utara sebagai upaya mitigasi bencana tsunami.

2. Perlunya disusun rencana kontinjensi tsunami bagi masyarakat yang terdapat pada wilayah laut utara Pulau Sulawesi jika terjadi gempabumi yang berpotensi tsunami.

3. Ketangguhan masyarakat menghadapi bencana akan terwujud jika seluruh komponen masyarakat dan pemerintah daerah memiliki kemampuan untuk mengurangi bahaya atau ancaman.

\section{UCAPAN TERIMA KASIH}

Ucapan terima kasih dicurahkan kepada semua pihak terkait, utamanya Kepala Pusat Gempabumi dan Tsunami yang memberikan izin untuk mengoperasikan pemodelan tsunami dengan menggunakan TOAST. Penulis juga mengucapkan terima kasih kepada Ibu Ernalem A. Bangun sebagai Dosen Universitas Pertahanan dan kepada Bondan Prakoso atas masukan dan bimbingan dalam membuat penelitian ini.

\section{DAFTAR PUSTAKA}

BMKG. (2010). Konsep dan implementasi InaTEWS. Jakarta: BMKG.

Global Earthquake Monitoring Processing Analysis. TOAST. Diunduh di https://www.gempa.de/products/toast/ tanggal 25 Desember 2020].

Hall, R \& Wilson, M. E. J. (2000). Neogen Sutures in Eastern Indonesia, Journal of Asian Earth Science 18, SE Asia Research
Group, Department of Geology, Royal Holloway University of London, United Kingdom.

Maarif, Syamsul. (2012). Pikiran dan gagasan penanggulangan bencana di Indonesia: membangun masyarakat tangguh menghadapi bencana sebagai antisipasi ancaman gempabumi. Jakarta: BNPB.

Setiyono, Urip. (2018). Buku katalog gempabumi signifikan dan merusak 1821-2017. Jakarta: BMKG.

Socquet, A., Simons, W., Vigny, C., McCaffrey, R., Subarya, C., Sarsito, D., Ambrosius, B. and Spakman, W., (2006). Microblock rotations and fault coupling in SE Asia triple junction (Sulawesi, Indonesia) from GPS dan earthquake slip vector data. Journal of Geophysical Research: Solid Earth, 111(B8).

Tim Pusgen. (2017). Buku peta sumber dan bahaya gempa Indonesia tahun 2017. Bandung: Litbang Perumahan dan Pemukiman Kementerian PUPR.

Undang-Undang Republik Indonesia Nomor 24 Tahun 2007 tentang Penanggulangan Bencana.

Wahyu, R. O., Djamaluddin, R., Gybert, E., Mamuaya., Tatok Yatimantoro., dan Priyobudi. (2018). Pemodelan inundasi tsunami di sepanjang pesisir Kota Manado akibat gempabumi m8,5 di zona subduksi Sulawesi Utara. Jurnal Meteorologi dan Geofisika, 19(1), 13-18. 